\title{
COMPLEXIDADE ECONÔMICA E DO INVESTIMENTO PÓS POLÍTICAS INDUSTRIAIS
}

\author{
Sávio de Carvalho Araújo \\ Economista pela Universidade Federal de Uberlândia. \\ Endereço: Rua Everson Roberto de Sousa, 91, Bairro Jardim América II, Uberlândia - MG \\ CEP: 38.401-720 E-mail: sca_carvalhoaraujo@hotmail.com
}

\section{RESUMO:}

Este trabalho busca analisar a evolução e a relação pós retomada das políticas industriais, em 2003, com investimentos na economia brasileira, com enfoque para a indústria de transformação, com os conceitos de complexidade econômica, aqui desdobrado também em um indicador de complexidade dos investimentos. Ao longo dos 15 anos de análise, tanto os índices de complexidade econômica como de complexidade do investimento apresentaram involução, inclusive com a retração da posição do Brasil frente a outros países. Assim, os setores de maior conteúdo tecnológico, demandantes de uma cadeia de produção mais densa não delinearam a trajetória de desenvolvimento prevista nas medidas executadas, mantendo e, em parte, acirrando as características de baixa densidade e complexidade da indústria nacional.

PALAVRAS-CHAVE: Investimento; Indústria; Complexidade Econômica.

\begin{abstract}
:
This research intends to analyze the evolution and the relation of the industrial policies in Brazilian economy after it is recovery, in 2003. The work have it's focus on the transformation industry, applying concepts of economic complexity witch as well unfold an index of investment complexity. During 15 years of analysis both economic complexity and investment complexity presents constant decrease, with a decreasing position of Brazil in the global ranking. Therefore the sectors with an higher technological content, witch demand a denser production chain, didn't previewed the development trajectory of the executed measures, but keeping and intensifying the low density characteristic and complexity of national industry.
\end{abstract}

KEYWORDS: Investment; Industry; Economic Complexity.

JEL: L52; L60; O25 


\section{INTRODUÇÃO}

As políticas industriais no Brasil tornaram a figurar como elementos de iniciativas públicas no início dos anos 2000, após uma década de 1990 com pouca ou nenhuma ação nesta direção. O cenário no qual o governo voltou a desenvolver estas medidas, no entanto, era de dificuldades no ambiente econômico, em que se observavam quatro fatores importantes: depreciação cambial, pressões no Balanço de Pagamentos, perda de expressividade da indústria e baixo nível de investimentos.

O diagnóstico delineado pelo governo era o que a estrutura produtiva no Brasil carecia de maior densidade produtiva, de um maior nível de inovação, que apresentava um perfil exportador muito concentrado em grandes empresas, impedindo a acesso ao mercado externo das pequenas e médias companhias, e ainda carente de uma infraestrutura capaz de dotar a economia brasileira de maior competitividade.

No intuito de superar estes entraves, as novas políticas industriais, iniciadas com a PITCE (Política Industrial, Tecnológica e de Comércio Exterior), tinham na dinâmica do investimento um fator preponderante a ser estimulado, pois o enxergavam como o elemento dinâmico do desenvolvimento econômico, capaz de agregar maior valor ao produto e aumentar a produtividade da economia de modo generalizado, reverberando, sobretudo, na atividade industrial.

Assim, este trabalho busca contribuir para uma melhor compreensão acerca da dinâmica entre os investimentos industriais e a complexidade econômica do Brasil, à luz dos recentes esforços levados a cabo pelo governo, para retomar o nível de competitividade e proeminência da indústria brasileira no produto e renda nacionais.

Vale ressaltar que uma melhor cognição sobre a complexidade econômica é crucial para a compreensão das relações econômicas contemporâneas, seja entre países, ou internamente às cadeias de valor nacionais. A intensa interdependência entre os elos produtivos, proporcionou um ambiente dinâmico, difícil de ser trabalhado pelos conceitos tradicionais de desenvolvimento e de economia industrial (RODRIK, 2004).

Novas abordagens, capazes de analisar as relações produtivas tais como elas hoje se portam, vêm suprir uma lacuna teórica e metodológica de entendimento, não só da indústria, mas de todo o aparato produtivo da economia. A abordagem aqui realizada busca, em trabalhos recentes, subsídios para uma interpretação alternativa da questão industrial no Brasil, ainda muito calcada em concepções tradicionais, muitas vezes, pouco aderentes ao cenário posto.

O texto está estruturado em outras três seções além desta breve introdução. A segunda trata das políticas industriais adotadas pelo governo brasileiro a partir dos anos 2000. A terceira parte se debruça sobre o conceito e apresenta algumas evidencias para o Brasil do debate acerca da complexidade econômica e do investimento. Por sua vez, a última parte sintetiza o trabalho realizado à guisa de conclusão.

\section{AS NOVAS POLÍTICAS INDUSTRIAIS}

Ao longo das décadas, as políticas industriais serviram como ferramentas importantes para a garantia do crescimento e do desenvolvimento econômico em diversos países, especialmente ao estimular, entre as décadas de 1970 e 1980, a industrialização

RE\&D Econ. e Desenv., Santa Maria, vol. 29, n.1, p. 630 - 643, jan. - jul. 2017 
das economias de baixa renda da América Latina e Ásia, incorporando-as ao mercado global de manufaturas. Não obstante, o final do século XX marcou o declínio destas medidas (WARWICK, 2013), as quais apenas voltaram à baila no Brasil, em meados da década de 2000.

Rodrik (2004) defende que nem a agenda de desenvolvimento puramente guiada pelo comportamento mercadológico, nem os modelos fortemente calcados em iniciativas governamentais, tendem a apresentar bons resultados. Segundo o autor, a articulação de informações entre a iniciativa privada e pública podem produzir excepcionais resultados na coordenação das políticas de desenvolvimento econômico. Não obstante, esta interação implicaria a possibilidade de degeneração da máquina estatal em torno de ações corruptivas.

Tendo em vista o "ressurgimento" do interesse pelas políticas industriais em todo o mundo no decorrer dos últimos anos (como na França em 2005, no Japão em 2010, na Coréia do Sul, na Holanda e na Turquia em 2011, dentre outros países), Warwick (2013) argumenta que algumas economias voltaram a adotá-las como ferramenta de estímulo econômico face a potencial estagnação advinda da crise financeira de 2008-9. Ressalta ainda que este acontecimento contribuiu para colocar em cheque a estabilidade do sistema financeiro, sobretudo, no que concerne aos fluxos de investimento, o que acometeria a capacidade de financiamento do setor real da economia.

É importante sublinhar que o termo "Política Industrial", ainda conforme Warwick (2013), passou a possuir abordagem diferente conforme o intuito do país em questão. No caso francês, por exemplo, as medidas adotadas centraram-se na atuação de fundos públicos de investimento e inovação. Já no modelo turco, e também brasileiro, a política governamental empreendeu medidas mais complexas, abarcando desde estímulos ao investimento, até novos mecanismos de regulamentação e fiscalização. Como característica coincidente entre estes diversos modelos, menciona-se a necessidade dos órgãos estatais de suprir a contração observada em algumas cadeias industriais, o que fomentou ações de estímulo de demanda, abarcadas no contexto destas novas políticas industriais.

No que concerne às políticas industriais desenvolvidas a partir de 2003 no Brasil, pode-se argumentar que todas abarcaram o desenvolvimento técnico-científico em suas metas. Em comum, observa-se o intuito em aprimorar a estrutura de produção do país, aumentando o nível de complexidade e, logo, o valor adicionado da produção doméstica.

A PITCE vigorou de 2004 a 2007, com o foco principal de modernizar e fortalecer os instrumentos institucionais que induzissem os agentes a investirem em inovação por meio de medidas horizontais de estímulo, combinadas com ações verticais direcionadas a segmentos estratégicos de maior teor agregado (semicondutores, softwares, bens de capital e fármacos). Além disso, as exportações destes segmentos prioritários deveriam ser incentivadas e as companhias nacionais seriam induzidas a uma postura mais proativa no exterior (PITCE, 2003). O conjunto de medidas adotadas pelo governo no âmbito desta política industrial visava a enfrentar o agudo ambiente econômico do início da década, marcado pela depreciação do real e pelas pressões no balanço de pagamentos.

Entre 2008 e 2010, vigorou uma nova política industrial, em substituição a PITCE. A Política de Desenvolvimento Produtivo (PDP) objetivava manter o bom desempenho da economia nacional, auxiliado pela dinâmica econômica internacional, pelas reservas em ascensão e pela melhora dos termos de troca. Soma-se a isto, o bom

RE\&D Econ. e Desenv., Santa Maria, vol. 29, n.1, p. 630 - 643, jan. - jul. 2017 
momento do mercado interno, a expansão de crédito, especialmente para as famílias de renda mais baixa, o mercado de trabalho aquecido, com a taxa de desemprego em mínimas históricas, e a renda doméstica fortalecida por uma política de ganhos reais do salário mínimo, e pelo acelerado ciclo de investimentos, comparável, inclusive, ao vivenciado nos anos 1980s (KUPFER et al., 2013).

A PDP atuou em torno de quatro macrometas, que buscavam em um horizonte de três anos findos em 2010: i) acelerar as inversões em capital fixo; ii) estimular mecanismos de inovação nas empresas, elevando a participação do setor privado no gasto com P\&D; iii) fomentar a inserção do Brasil no comércio mundial; e iv) majorar o número de micro e pequenas empresas exportadoras. Tal como a PITCE, o conjunto de medidas adotadas pelo governo no escopo deste plano conjugava ações verticais e horizontais no intento de manter o desenvolvimento de indústrias estratégicas para o futuro do país.

No arcabouço dos setores-chave para a PDP, estavam-se o complexo da saúde, a indústria de Tecnologia da Informação e Comunicação (TIC), de energia nuclear, de material de defesa, de nanotecnologia e a de biotecnologia. Para além destes setores, outras cadeias produtivas foram favorecidas ou pelos programas de fortalecimento da competitividade ou pelos programas de consolidação e expansão, este último voltado a setores maduros, como mineração, aço, celulose e papel e aeronáutico.

Em 2011 o governo federal implementou o Plano Brasil Maior (PBM). Diferente das políticas anteriores, o PBM foi essencialmente um conjunto de medidas de defesa da indústria nacional, com o objetivo de enfrentar os sinais de deterioração da atividade econômica, expressos pelo menor crescimento do produto nacional.

A PBM apresentava dez metas principais, assentadas em torno de medidas horizontais e verticais, tal qual suas predecessoras. De modo geral, seus objetivos podem ser sintetizados em quatro pontos centrais de articulação: i) a identificação e fortalecimento de competências críticas para a economia nacional; ii) o aumento da produtividade e da densidade tecnológica nas cadeias de valor nas quais o país se inseria; iii) a expansão dos mercados internos e externos das companhias nacionais, via diversificação produtiva e apoio a internacionalização; e iv) a garantia do crescimento econômico social e ambientalmente sustentado (MDIC, 2011).

O impacto de todas as três políticas (PITCE, PDP e PBM) sobre o investimento na indústria brasileira não surtiu, como um todo, os efeitos dinamizadores esperados, pois mesmo as carteiras de investimento de setores prioritários sofreram retração. Ademais, a concentração das inversões em alguns setores parece ter sido motivada pelas próprias ações governamentais, pois não se percebe grande coordenação entre os estímulos de crédito para investimento e os setores chave das políticas econômicas.

Em função da precária capacidade de financiamento de longo prazo no país a partir de mecanismos privados, como o mercado de ações e títulos corporativos, o BNDES desponta como a principal fonte de fundos para grande parte da indústria nacional. Logo, o impacto da utilização desta instituição na coordenação da política industrial assumiu consideráveis proporções. Não obstante, foram os setores de médiabaixa e baixa tecnologias que ampliaram sua participação nos desembolsos totais da instituição, especialmente os vinculados à indústria petrolífera, com expansão de 11\% para $28 \%$, e extrativa, de $3 \%$ para $5 \%$, tal como apresentado no Gráfico 1 .

RE\&D Econ. e Desenv., Santa Maria, vol. 29, n.1, p. 630 - 643, jan. - jul. 2017 
Gráfico 1 - Evolução e composição dos desembolsos do BNDES - 2001 a 2015

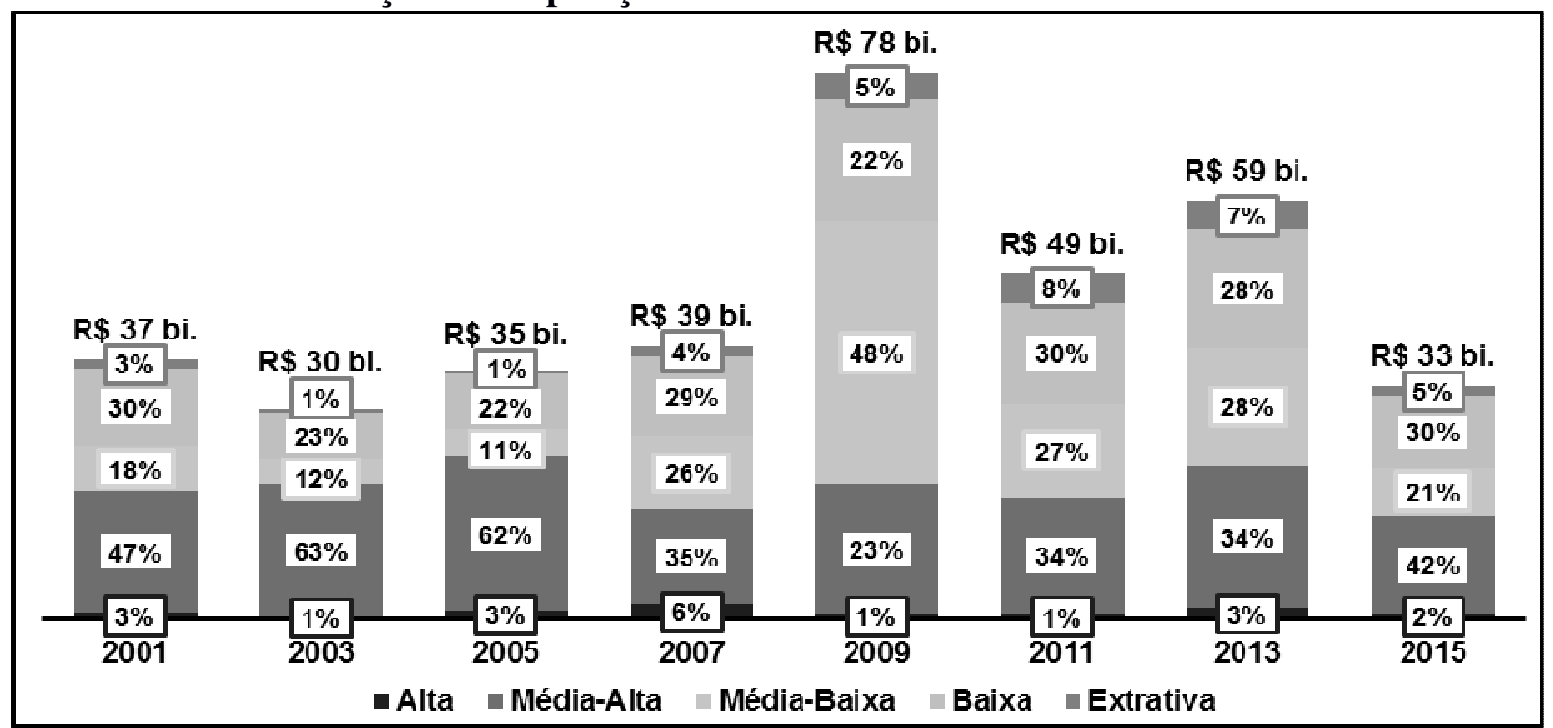

Fonte: Elaboração própria a partir dos boletins operacionais do BNDES.

Obs.: Os valores em reais estão deflacionados para 2014 a partir do IPA-EP.

Especificamente no âmbito da PITCE, Vermulm e de Paula (2007) afirmam ser possível observar uma insuficiência de recursos à disposição dos setores prioritários, e que não houve um maior direcionamento dos aportes do banco para essas indústrias. Segundo Arbix (2010, pág. 28-29), “o BNDES, historicamente, respondeu pelas obras de infraestrutura, pelo financiamento das grandes empresas e (...) pelas exportações", em operações de perfil conservador, que se mostraram insuficientes face à necessidade de incentivar mecanismos de $\mathrm{P} \& \mathrm{D}$ e setores com maior risco.

$\mathrm{Na}$ PITCE, por exemplo, figuravam como segmentos prioritários a serem incentivados as indústrias farmacêutica, de softwares e de bens de capital, os quais apresentaram ganhos de participação apenas marginais na carteira de crédito do BNDES. Comportamento pouco diferente foi observada nos planos seguintes, com a PDP e o PBM, inclusive porque dentre os objetivos delineados a partir de 2008, se encontrava o fortalecimento de indústrias tradicionais, no intento de ampliar a inserção externa do país. Desta forma, os setores mais complexos da atividade econômica, ainda que mais frágeis, passaram a compartilhar os esforços econômicos com segmentos como metalúrgico e de papel e celulose, menos dinâmicos tecnologicamente.

Neste sentido cabe mencionar que, não só a indústria de transformação perdeu relevância, mas internamente se observa uma reorientação qualitativa de seus investimentos em torno de segmentos de média-baixa e baixa tecnologia, mormente aqueles vinculados a produtos derivados de petróleo. A indústria a automotiva, importante setor do agrupamento de média-alta tecnologia, por exemplo, sofreu retração em sua parcela específica de investimentos entre 1996 e 2014.

\section{A EVOLUÇÃO DA COMPLEXIDADE ECONÔMICA E DO INVESTIMENTO NA ECONOMIA BRASILEIRA}

RE\&D Econ. e Desenv., Santa Maria, vol. 29, n.1, p. 630 - 643, jan. - jul. 2017 
Não obstante, deve-se destacar que o meio pelo qual o desenvolvimento econômico perpassa a estrutura produtiva vai muito além do debate da concentração setorial da produção ou de indicadores econômicos isolados. Tomando por base os trabalhos de Hidalgo et al. (2007) e Hidalgo e Hausmann (2009), pode-se entender o processo de desenvolvimento econômico como o mecanismo pelo qual uma economia adquire novas capacidades para produzir, e consequentemente exportar, novos tipos de produtos. Acumular novas habilidades é, desta forma, crucial para que produtos mais complexos sejam, então, produzidos pelo país em questão. Logo, a problemática da complexidade econômica deve ser considerada quando se intenta avaliar o ambiente econômico.

Ainda segundo esses autores, deve-se ponderar que existem retornos crescentes na dinâmica de diversificação, pois as economias dotadas de menores capacidades produtivas possuem incentivos reduzidos para desenvolver novas habilidades. O catching up, portanto, não resultaria de um comportamento passivo frente à atuação do mercado, pois o desenvolvimento requer não apenas incrementos marginais nos produtos já ofertados, mas também, e principalmente, a acumulação e reorganização de novas atividades associadas a maiores níveis de produtividade.

Para isto, os autores desenvolveram um indicador com o objetivo de auferir a complexidade econômica de determinado país: o Índice de Complexidade Econômica $(E C I)$. Uma vez que os bens são resultados das combinações das capacidades de uma economia, seria possível auferir seu nível de complexidade produtiva a partir dos bens por ela produzidos. Ainda mais, por hipótese, assume-se que os exportadores de um mesmo produto, que o fazem com Vantagem Comparativa Revelada ( $R C A)$ possuem dotações produtivas em comum.

A construção do ECI apresenta uma formulação matemática de considerável simplicidade, tal como exposto em Hidalgo e Hausmann (2009). O índice parte de duas características básicas, a "ubiquidade" e a "diversidade". A primeira está relacionada à quantidade de países que produzem determinado produto, de tal forma que produtos ubíquos devem ser produzidos e exportados por muitas economias. Já a segunda se vincula à dispersão da produção de uma economia entre os diversos bens possíveis de serem produzidos. Logo, o processo pelo qual o desenvolvimento se efetiva, e por consequência, pelo qual produtos mais complexos passam a ser produzidos, está relacionado à diversificação e não à especialização, pois os indivíduos tendem a se especializar para combinar conhecimentos de modos variados, o que produz uma dualidade de diversidade a nível macro e especialização a nível micro (HAUSMANN e HIDALGO, 2014).

Apesar de suportado por robustos testes econométricos, é imprescindível ter em mente que nenhum debate da seara econômica é livre de controvérsias, de tal forma que são realizadas críticas contundentes acerca deste indicador, sendo a mais severa delas empreendida pelos próprios autores do índice (HAUSMANN e HIDALGO, 2009). A argumentação reside em torno de um problema de congruência, pois quando o limite de análise das $R C A s$ é reduzido, é possível observar que os países industrializados produzem e exportam bens de quase todas as classificações e, efetivamente, seus padrões de especialização possuem viés pela falta de diversificação dos países em desenvolvimento, e não necessariamente pela ausência das economias industrializadas em setores menos desenvolvidos. Logo, os países subdesenvolvidos que apresentam $R C A$ em algumas

RE\&D Econ. e Desenv., Santa Maria, vol. 29, n.1, p. 630 - 643, jan. - jul. 2017 
poucas indústrias apenas terão refletido no indicador a sua condição de grande especialização produtiva (ver também Vasconcelos, 2013).

Ressalta-se ainda que o ECI, tal como desenvolvido originalmente por esses autores, leva em conta todos os produtos exportados pela economia em tela, não distinguindo entre a classificação do setor que o produziu. Em outras palavras, considerase tanto as exportações oriundas da indústria de transformação quando as originadas da indústria extrativa, agropecuária e serviços, o que "contaminaria" a análise proposta neste estudo, qual seja a de caracterizar a dinâmica da indústria de transformação ${ }^{1}$. Assim, será utilizada uma variação do indicador original que abarque em seu cálculo apenas os produtos referentes a este segmento produtivo, seguindo-se todos os demais passos da metodologia original.

Cabe destacar que diferente do índice apurado pelo Observatory of Economic Complexity $(O E C)$, que utiliza a metodologia de categorização de produtos Standard International Trade Classification Rev. 4 (SITC Rev. 4) desagregada a seis dígitos, este estudo utilizou a classificação do Harmonized System Rev. 1996 (HS96) a quatro dígitos, em função da disponibilidade de um software estatístico suficientemente robusto para a leitura de dados mais detalhados. Não obstante, os efeitos de tal mudança não devem comprometer o resultado geral do estudo, uma vez que o ECI é um valor absoluto, cujo interesse reside na análise do comportamento da série, bem como no ordenamento entre os países analisados no momento em questão.

Por outro lado, a menor desagregação dos dados pode produzir ruídos no nível do índice quando realizada uma comparação dos indicadores, prejudicando a perfeita aderência entre o "indicador original" e o aqui calculado. Contudo, em termos de tendência e variação, não foram observadas grandes discrepâncias entre os dois trabalhos.

$\mathrm{O}$ indicador de complexidade permite uma compreensão mais apurada do adensamento das cadeias de produção de uma economia, ou em outras palavras, do quão inter-relacionados estão seus diversos setores produtivos. Este aspecto é de suma importância tanto para a caracterização econômica ao longo do tempo como para o balizamento de ações públicas no âmbito industrial.

Comumente utiliza-se a relação Valor da Transformação Industrial / Valor Bruto da Produção Industrial (VTI/VBPI) como indicador de referência para o nível de adensamento produtivo, assim como explícito, por exemplo, nas macrometas da PDP e do PBM. Não obstante, segundo Torres e Silva (2012), esta proxy apresenta sérias fragilidades, pois: i) a razão VTI/VBPI é fortemente sensível às variações cambiais; e ii) "não é capaz de informar qual indústria tem uma cadeia de produção mais densa no país, ou seja, qual apresenta maior produção de bens finais e, principalmente, dos materiais, insumos e componentes utilizados na fabricação do produto final".

Apesar de menos intuitivo, delinear metas em torno do ECI poderia contribuir para um planejamento de ações mais assertivas quando o objetivo posto fosse o de incentivar os "elos" produtivos de determinados setores chave. Tal indicador ainda permitiria a avaliação produto a produto da pauta de produção e exportação, pois carrega recursivamente o Índice de Complexidade do Produto $(P C I)$, passível de ser utilizado

\footnotetext{
${ }^{1}$ Neste estudo, foi utilizada a metodologia de classificação de produtos Harmonized System Rev. 1996 (HS96) a quatro dígitos, no qual a indústria de transformação compreende os capítulos 11, 16-24 e 28-97.
}

RE\&D Econ. e Desenv., Santa Maria, vol. 29, n.1, p. 630 - 643, jan. - jul. 2017 
como balizador, por exemplo de setores prioritários para a concessão de crédito ou outras modalidades de incentivos dentro do escopo de objetivos de uma Política Industrial.

A comparação entre os resultados observados do indicador geral, ou seja, referente a todos os setores da economia, e aquele restrito a indústria de transformação, proporciona um entendimento contundente da evolução da atividade manufatureira frente aos desdobramentos gerais da economia. Desta forma, é possível observar no Gráfico 2 a evolução da complexidade econômica brasileira para a os anos de 2000 a 2014. Em função da disponibilidade de dados no momento de execução deste estudo, não foi possível a consolidação das informações de comércio exterior e, consequentemente a obtenção do $E C I$, para os anos posteriores.

Gráfico 2 - Índice de Complexidade Econômica - 2000 a 2014

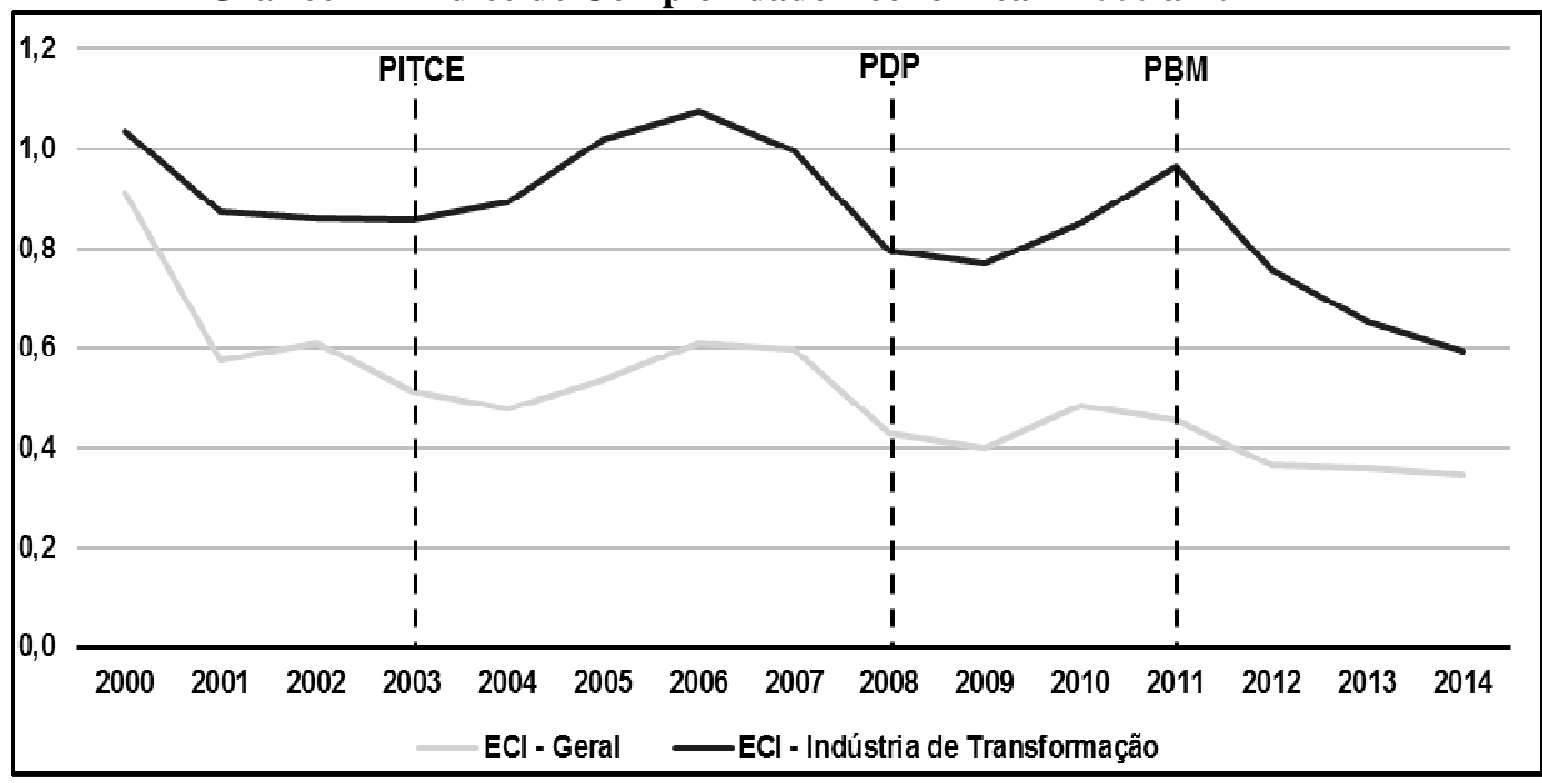

Fonte: Elaboração própria.

Obs.: Os dados utilizados para a construção do indicador não estão apresentados no trabalho em função da grande quantidade de observações.

Destaca-se a grande proximidade no nível dos dois indicadores no início da série, a qual diminui ao longo do tempo com uma ampliação da distância entre a complexidade geral e a da indústria de transformação, sobretudo, a partir de 2002. Não obstante o "descolamento" inicial dos índices, as evoluções das variáveis são muito similares, mantendo a mesma proporção de diferença entre os setores produtivos.

Importante relembrar que o objetivo final de todas as três políticas desenvolvidas neste período era o de intensificar o nível tecnológico e adensar as cadeias produtivas brasileiras. Assim, o esperado era que o ECI apresentasse uma evolução em seu nível, delineando uma tendência de crescimento que, efetivamente não foi observada. A exceção dos três primeiros anos da PITCE e dos dois últimos da PDP, o indicador apresentou sucessivas quedas findando $2014 \mathrm{em}$ patamar inferior ao do início do período de análise, em 2000.

Assim, é razoável afirmar que, ao menos em termos de desenvolvimento produtivo e tecnológico, os resultados auferidos pelas Políticas Industriais brasileiras dos

RE\&D Econ. e Desenv., Santa Maria, vol. 29, n.1, p. 630 - 643, jan. - jul. 2017 
anos 2000 e 2010 foram muito aquém do esperado. Deve-se ponderar, contudo, que apesar do seu relativo "insucesso" a não implementação destas medidas poderia ter se refletido em uma retração ainda maior da complexidade econômica nacional.

Poder-se-ia argumentar ainda que o efeito preço poderia ter exercido um efeito "contaminante" do indicador de complexidade para a economia brasileira, dada da sua forte relação com os mercados de commodities. Em outros termos, a elevação do preço dos produtos básicos implicaria em um ganho de peso relativo destes segmentos nas exportações brasileiras, "mascarando" o ganho de inserção externa de outros setores. Não obstante, observa-se que a tendência de retração do ECI se mantem mesmo após o ciclo de alta das commodities.

Não é possível descartar o impacto dos preços dos insumos básicos para a evolução do índice de complexidade, no entanto o principal fator explicativo para esta deterioração reside na incapacidade de desenvolvimento de indústrias de elevado teor tecnológico, e de novos engajamentos intra e inter cadeias industriais.

Comparada às demais economias do globo, o Brasil retrocedeu da $29^{\mathrm{a}}$ colocação em 2000 para a 32 em 2014 (segundo a formulação original do indicador), sendo que a partir de 2008 , por vezes o país figurou abaixo da $50^{\mathrm{a}}$ posição, descrevendo, de modo geral, uma trajetória de queda. O Gráfico 3 apresenta a evolução da posição brasileira no ranking mundial de complexidade entre os anos de 2000 e 2014 conforme a formulação original do indicador. Destaca-se que o resultado de 2014 é preliminar, em função da divulgação dos dados oficiais.

Gráfico 3 - Posição brasileira no ranking mundial do ECI - 2000 a 2014

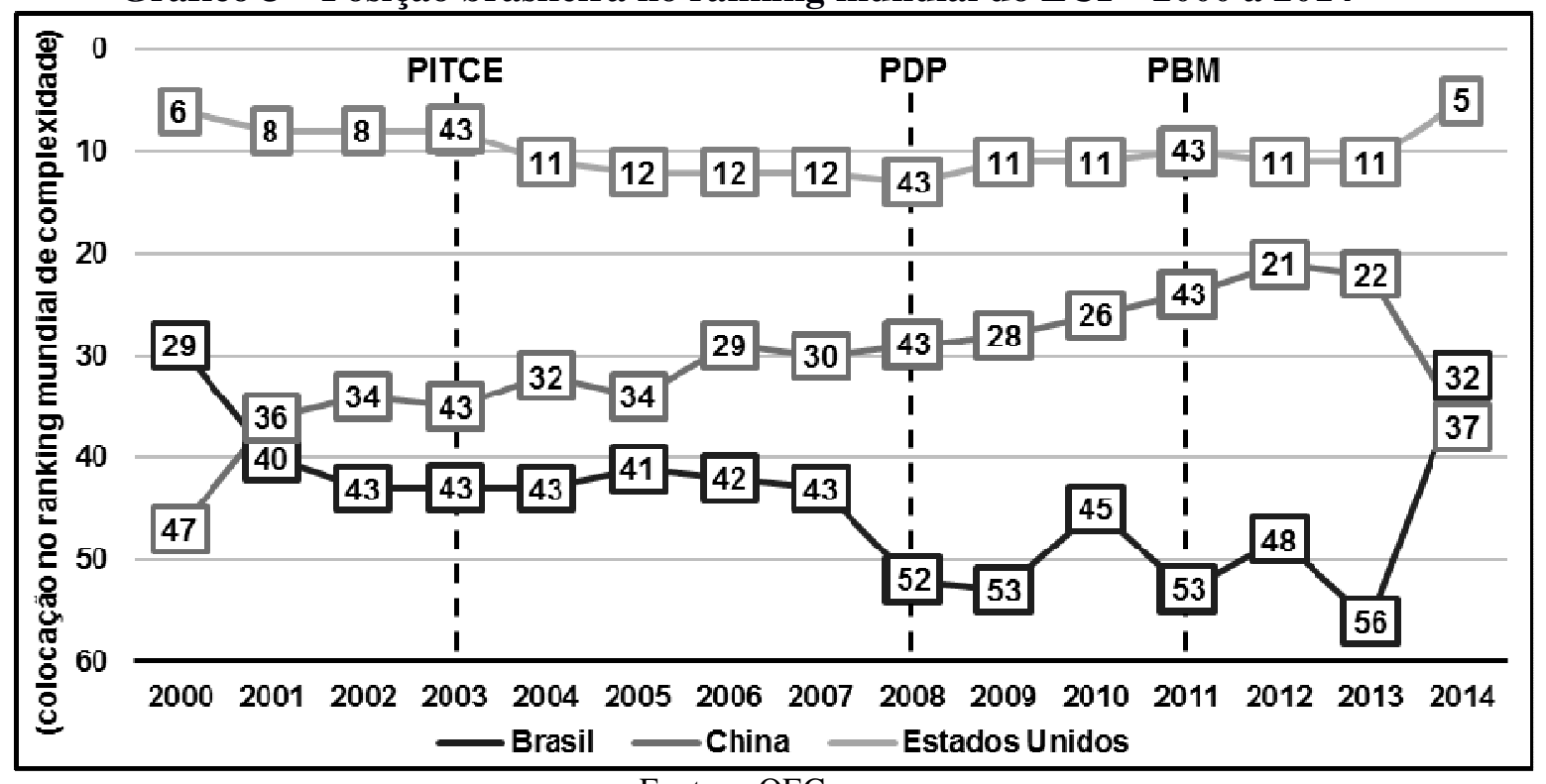

Cabe a ressalva que a deterioração neste ranking significa não apenas a perda de complexidade econômica comparado aos demais países, mas também uma deterioração da capacidade de crescimento da renda no longo prazo. Isto porque uma vez que economias menos complexas possuem dificuldades no desenvolvimento de links produtivos, os investimentos em setores tecnologicamente intensivos apresentam uma

RE\&D Econ. e Desenv., Santa Maria, vol. 29, n.1, p. 630 - 643, jan. - jul. 2017 
tendência de fixação em países com melhor ambiente produtivo, ou em outros termos, que possuam maiores capacidades de inter-relacionamento industrial. Em outras palavras, as atividades demandantes de mais conexões apresentam dificuldades de inserção em economias pouco complexas, implicando em um reforço ao longo do tempo da disparidade entre os países mais e menos complexos (ver HAUSMANN e HIDALGO, 2009).

Tendo em vista que as políticas levadas a cabo pelo governo, desde a PITCE, visavam à consolidação de setores de alta e média-alta tecnologia, assim como a ampliação de suas capacidades exportadoras, pode-se inferir que, ao menos, no tocante ao estímulo ao desenvolvimento de novas indústrias, os resultados não foram ao encontro do esperado, uma vez que não se observou o adensamento produtivo almejado pela ação governamental.

A indústria de alta tecnologia, por exemplo, perdeu 7 p.p. de participação no VTI total, chegando a 6\% em 2014, enquanto o segmento de média-alta tecnologia permaneceu praticamente no mesmo patamar, com queda de 2 p.p. ao longo do período, para $22 \%$. Nenhum dos setores prioritários das políticas industriais (semicondutores, softwares, bens de capital e fármacos) logrou ampliar sua expressividade na indústria nacional.

No intuito de analisar o comportamento recente dos investimentos na indústria brasileira, optou-se pela extensão conceitual do ECI, mediante a construção de um novo indicador capaz de auferir a dinâmica desta variável. Cabe menção que apesar da profusa literatura sobre políticas industriais e desenvolvimento produtivo, poucos trabalhos se debruçam sobre a inter-relação entre esses assuntos e as inversões na indústria de transformação. É, portanto, nesta relação que este índice visa se inserir.

Para a construção deste indicador, doravante ICI (Índice de Complexidade do Investimento $)^{2}$, optou-se pela utilização do $P C I$, apresentado em Hidalgo e Hausmann (2009) como fator de medida, o qual foi ponderado pela participação relativa de cada setor econômico no total dos investimentos para cada ano conforme os dados de mutação do ativo imobilizado da PIA.

Cabe comentário que a construção do ICI, implicou em uma série de conversões entre diferentes metodologias de agregação de produtos, mormente SITC Rev. 4 para CNAE 1.0 e 2.0, de tal forma que algumas informações foram perdidas durante o processo. Optou-se ainda pela não utilização da metodologia de agregação HS96, tal qual na elaboração dos indicadores anteriores, pela dificuldade de obtenção de um dicionário eficaz para a realização de sua equivalência com a CNAE (Classificação Nacional de Atividade Econômicas). Para o ano de 2014, não foi possível o cálculo da variável em função da defasagem entre a divulgação dos resultados e a conclusão deste estudo, já para o período 2000-2002, a grande perda de dados no processo de conversão das bases inviabilizou a elaboração do índice.

O Gráfico 9 apresenta os resultados obtidos para o indicador tanto para o investimento na indústria geral (extrativa e transformação) quanto para o ICI restrito ao

\footnotetext{
${ }^{2}$ Em termos formais pode-se definir este indicador como: $I C I=\sum_{i=1}^{n}\left(S_{i} \cdot P C I_{i}\right)$, em que $S_{i}$ é a participação dos investimento no setor $i$ e $P C I_{i}$ é o Índice de Complexidade do Produto $i$.
}

RE\&D Econ. e Desenv., Santa Maria, vol. 29, n.1, p. 630 - 643, jan. - jul. 2017 
segmento de manufatura. Tal qual no $E C I$ e no $P C I$, ressalta-se que o valor deste índice é um número absoluto, apenas importando o seu comportamento ao longo do período analisado.

Gráfico 4 - Índice de complexidade do investimento - 2003 a 2013

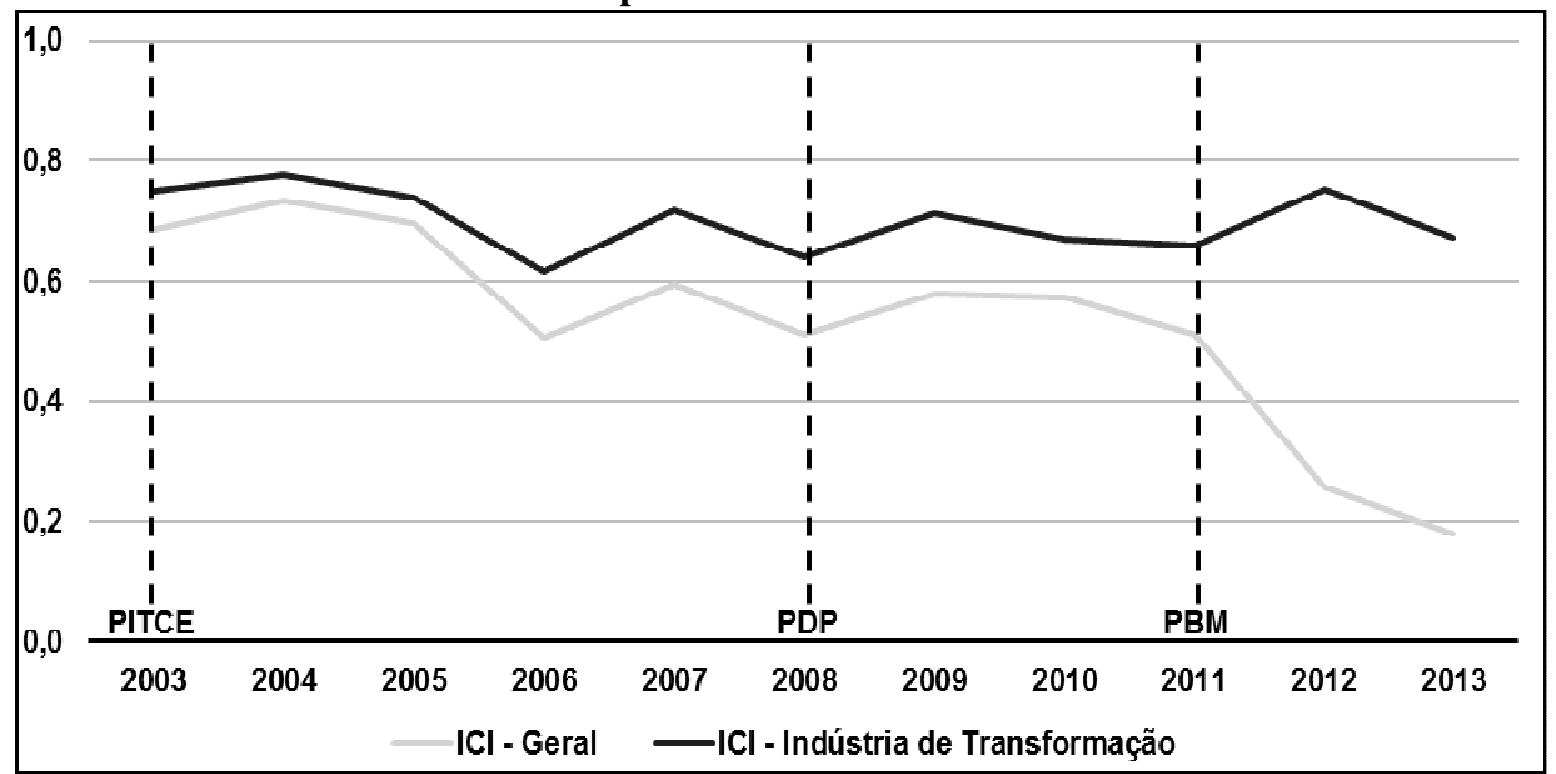

Fonte: Elaboração própria a partir dos dados da PIA/IBGE e do OEC.

Obs.: Os dados utilizados para a construção do indicador não estão apresentados no trabalho em função da grande quantidade de observações.

O ICI da indústria de transformação manteve-se praticamente estável ao longo de toda a série, com uma pequena tendência de queda. Com relação ao indicador agregado, apesar de ter acompanhado de perto as variações de seu congênere, a partir de 2011 passou a apresentar uma forte tendência de deterioração.

É importante ressaltar um aspecto destes indicadores, qual seja o fato de ignorarem o nível geral do investimento, uma vez que apenas levam em consideração sua composição interna. Desta forma, a discrepância observada entre os dois indicadores pós2011 pode ser justificada por uma queda mais que proporcional das inversões na indústria de transformação quando comparada aos demais setores produtivos. Assim, os setores com menor nível de complexidade passaram a somar porção maior do índice, pressionando por sua queda. Não obstante esta ressalva, a piora do quadro de investimento nacional permanece latente.

Ainda cabe argumentar que a manutenção nos mesmos patamares do ICI da indústria de transformação indica que, internamente a sua composição, seus investimentos não apresentaram melhora qualitativa, uma vez que caso novos setores, mais densos em tecnologia, tivessem se desenvolvido, o índice deveria apresentar uma melhora. Destarte, não só é possível depreender pelo não desenvolvimento de novas indústrias, mas também por uma manutenção das inversões em torno daquelas atividades de menor impacto dinamizador já existentes na estrutura produtiva nacional.

Mesmo com as ações do governo no sentido de fortalecer as cadeias de suprimento de insumos de elevado teor tecnológico para a produção de matérias-primas e

RE\&D Econ. e Desenv., Santa Maria, vol. 29, n.1, p. 630 - 643, jan. - jul. 2017 
combustíveis em território nacional (como a indústria de bens de capital), não foi observada uma resposta consistente do mercado com investimentos nestas atividades. Desta forma, a ampliação do adensamento produtivo prevista pelo governo não foi, efetivamente, observada, refletindo a deterioração do ICI nacional.

Assim, tal como observado em relação ao ICE, pode-se depreender pela pouca efetividade das novas políticas industriais (PITCE, PDP e PBM) para a dinamização do investimento em novas indústrias. Em parte, pode-se argumentar que a necessidade de retomar o nível de atividade econômica pré-crise, levou o governo, via BNDES, a ampliar de maneira não coordenada ao inicialmente previsto os desembolsos de crédito para indústrias tradicionais, notadamente no âmbito do PBM, justificando em parte o comportamento observado para os índices a partir de 2011.

Em outros termos, a articulação das ações de política industrial não contribuiu, de modo definitivo, nem para a melhoria quantitativa dos investimentos, uma vez que seu nível não atingiu os objetivos esperados, tendo nos últimos anos, inclusive, apresentado retração real, nem qualitativamente, pois as inversões ainda continuaram centradas em algumas cadeias produtivas, pouco intensivas em tecnologia e incapazes de produzir conexões inter e intra setoriais consistentes (spillovers).

De modo geral, tanto o indicador de complexidade do investimento quanto o de complexidade econômica apontaram para uma deterioração da situação da indústria de transformação nacional em todo o período de análise, a despeito das políticas empreendidas. Ressalta-se ainda, que em função do caráter de longo prazo dos investimentos, os resultados negativos observados no período recente devem implicar em um desempenho ruim para o sistema produtivo como um todo nos próximos anos, especialmente no tocante ao teor tecnológico e a geração de renda.

\section{CONSIDERAÇÕES FINAIS}

As transformações recentes da estrutura produtiva brasileira, influenciadas pelos eventos internos e externos dos últimos anos, contribuiu para o debate em torno de diversos pontos acerca da situação atual e das possibilidades futuras de desenvolvimento do setor produtivo nacional, sobretudo o tocante à indústria de transformação.

Assim, este trabalho intentou analisar o comportamento do investimento na indústria brasileira após a retomada das políticas industriais em 2003. Compreende-se que as inversões são elementos importantes para a explicação das tendências futuras de desenvolvimento de uma economia, sobretudo quando eles recaem sobre o setor produtivo. Desta forma, o entendimento de como o setor industrial nacional se relaciona com este indicador pode sinalizar importantes desdobramentos para os períodos vindouros.

Além disso, trabalhou-se a relação entre o comportamento dos investimentos produtivos com os conceitos de complexidade econômica, desenvolvido pelos núcleos de economia de Harvard e do Massachusetts Institute of Technology (MIT), e o de complexidade do investimento, formulado neste trabalho.

A partir do ano de 2003 o governo federal retomou a execução das políticas industriais, após um considerável período de ausências destas medidas na pauta do Estado. A primeira política desenvolvida, a PITCE, possuía uma forte vinculação com a

RE\&D Econ. e Desenv., Santa Maria, vol. 29, n.1, p. 630 - 643, jan. - jul. 2017 
conjuntura econômica vivenciada pelo país: de dificuldades no âmbito macroeconômico. Assim, as ações empreendidas em seu arcabouço visavam fortalecer e modernizar a produção brasileira como ferramenta para assegurar o desenvolvimento da economia brasileira no médio e longo prazo.

A partir de 2008, a PDP assumiu como a nova política industrial do país, desta vez em um ambiente mais estável e com boas perspectivas futuras. Suas ações visavam, diferentemente de sua antecessora, a manutenção de um padrão positivo de crescimento da economia conjugado a modernização do parque produtivo e a estímulos para a inovação.

Por fim, em 2011, o governo estabelece o PBM, em um contexto, novamente, de deterioração macroeconômica em que o setor produtivo começava a sentir os efeitos da crise mundial que afetava diversos mercados globais.

Apesar de buscarem fomentar os segmentos de maior valor agregado da economia, tais políticas industriais não obtiveram êxito em dinamizar os investimentos efetuados nestas áreas. Ao longo do período abordado, o perfil das inversões na atividade industrial apresentou expressiva piora, em linha com a deterioração dos indicadores de complexidade econômica e com o aumento da concentração destes recursos em alguns segmentos produtivos. Mesmo as ações verticais arroladas pouco surtiram efeito sobre a dinâmica de seus setores alvo, os quais permaneceram inexpressivos na matriz produtiva nacional.

É possível ainda observar uma evolução do escopo e das medidas de articulação das políticas industriais, desde a PITCE até o PBM, com maior articulação entre seus programas e ações de trabalho mais elaboradas. Todavia, ainda se percebem falhas de integração entre as diversas esferas de ação do governo, as quais ainda carecem de um maior horizonte de execução e mais vínculos com uma visão de desenvolvimento econômico nacional, destacada dos ciclos econômicos e das instabilidades do meio político-eleitoral nacional.

A crítica aqui realizada não recai sobre a opção do governo por retomar a execução de políticas industriais, uma vez que ainda que o comportamento do setor produtivo tenha sido aquém do objetivado, a não realização destas ações poderia ter implicado em uma involução ainda pior da indústria de transformação brasileira.

Entretanto, pode-se atribuir, em parte, ao próprio governo os resultados pouco expressivos obtidos pelas três políticas industriais desenvolvidas no período, em função de uma baixa coordenação entre suas esferas e ações. Ademais, como mencionado, o reduzido horizonte de ação das políticas indústrias pode ter contribuído negativamente para os resultados observados.

Como um todo, os investimentos apresentaram uma concentração em torno de setores com necessidade de entrelaçamentos produtivos mais reduzida. Esta transformação sugere, um rearranjo produtivo em curso na indústria brasileira, na qual as cadeias de produtos de alto valor agregado findaram por seguir uma tendência diversa daquela esperada pelo governo no âmbito das políticas industriais empreendidas.

Com relação ao nível de complexidade econômica, observou-se uma tendência involutiva, manifesta em uma sensível redução dos indicadores tanto para a economia geral como restrito a indústria de transformação. Este padrão de desenvolvimento se desdobra em um movimento de acirramento da dependência de commodities e dos setores de baixa e média-baixa tecnologia nas pautas de produção e exportação. O reflexo mais

RE\&D Econ. e Desenv., Santa Maria, vol. 29, n.1, p. 630 - 643, jan. - jul. 2017 
nítido deste movimento pode ser explicitado na queda consistente da colocação brasileira no ranking mundial de complexidade, da $29^{\mathrm{a}}$ colocação em 2000 para a $56^{\mathrm{a}}$ em 2013.

Os investimentos apresentaram tendência similar quando se enfoca a economia de um modo geral, com um reordenamento qualitativo de sua composição no sentido de reduzir o patamar de seu indicador de complexidade (ICI) em 73\% entre 2003 e 2013, para 0,1893. A realidade específica da indústria de transformação, contudo, foi de estabilidade, com diminuta variação ao longo do tempo, inclusive sem uma delineação clara de sua tendência.

Desta forma, este reordenamento inversionista na economia geral, deveu-se em grande medida a redução mais que proporcional dos aportes destinados à atividade manufatureira quando comparado ao restante dos setores econômicos, demonstrando uma maior resiliência dos setores menos intrincados tecnologicamente frente às flutuações econômicas.

\section{REFERÊNCIAS}

Arbix, G. Caminhos cruzados: rumo a uma estratégia de desenvolvimento baseada na inovação. Revista Novos Estudos, n. 87. 2010

Hausmann, R. e Hidalgo, C. A. The atlas of economic complexity: Mapping paths to prosperity. MIT Press, 2014.

Hidalgo, C. A. e Hausmann, R. The building blocks of economic complexity. Proceedings of the National Academy of Sciences, v. 106, n. 26, p. 10570-10575, 2009. Kupfer, D; Ferraz, J. C. e Marques, F. S. The return of industrial policy in Brazil. The Industrial Policy Revolution I - The Role of Government Beyond Ideology, cap. 5.1, p. 327-339. 2013.

MDIC. Brasil Maior. Inovar para competir. Competir para crescer. Plano 2011/2014. Ministério do Desenvolvimento, Indústria e Comércio Exterior, 2011. Disponível em: $<$ http://www.brasilmaior.mdic.gov.br>. Acesso em 17 de junho de 2015.

PITCE. Política Industrial, Tecnológica e de Comércio Exterior. Diretrizes. Disponível em: <http://www.abdi.com.br/Estudo/Diretrizes_PITCE.pdf $>$. Acesso em: 16 de outubro de 2014.

Rodrick, D. Industrial policy for the twenty-first century. UNIDO - United Nations Industrial Development Organization. 2004.

Torres, R. e Silva, H. C. Uma Crítica aos indicadores usuais de desindustrialização no Brasil. Anais do $\mathbf{4 0}^{\mathbf{0}}$ Encontro Nacional de Economia Anpec (2012).

Vasconcelos, T. C. O índice de complexidade econômica: uma revisão teórica e aplicações ao caso brasileiro. (Monografia) Universidade de Brasília - UnB, Faculdade de Administração, Contabilidade e Economia - FACE. 2013.

Vermulm, R. e De Paula, T. B. O desafio do futuro: as políticas para a ciência, tecnologia e inovação". Ln: BOCCHI, J. I. e MARQUES, R. M. (Organizadores) Desafios para o Brasil: como retornar o crescimento econômico nacional? São Paulo, Saraiva. 2007. Warwick, K. Beyond Industrial Policy: Emerging Issues and New Trends", OECD Science, Technology and Industry Policy Papers, No. 2, OECD Publishing. 2013.

RE\&D Econ. e Desenv., Santa Maria, vol. 29, n.1, p. 630 - 643, jan. - jul. 2017 